\title{
School Meals and Educational Outcomes in Rural Ethiopia
}

\author{
Robert Poppe Markus Frölich Getinet Haile
}

Revised version - March 02, 2017

\begin{abstract}
We investigate the relationship between providing school meals programme and educational outcomes in Ethiopia. Using data from school catchment areas across rural Ethiopia, the paper examines the role played by programme modalities and their implementation. The results indicate that supplementing on-site school meals with takehome rations can be beneficial for concentration, reading, writing and arithmetic skills. The timing of the distribution of school meals is also found to play an important role.
\end{abstract}

Keywords: School Meals, Learning Achievement, Cognitive Development, Ethiopia

JEL classification: I20, I21, I38, O55

Robert Poppe: Deutsche Gesellschaft fuer Internationale Zusammenarbeit (GIZ), robert.poppe@giz.de

Markus Frölich: Center for Evaluation and Development (c4ed) and University of Mannheim, froelich@uni-mannheim.de

Getinet Haile: University of Nottingham and Institute of Labor Economics (IZA), getinet.haile@nottingham.ac.uk

Acknowledgements: We thank the editors and two anonymous reviewers for helpful comments and suggestions. We thank conference participants at the German Economic Association's Research Committee on Development Economics (AEL) Conference 2012 and the 2012 CSAE Conference, Oxford University, and seminar participants at the UN-WFP Country Office in Addis Ababa, the Ethiopian Development Research Institute (EDRI) and University of Mannheim for valuable comments on earlier versions of the paper. Robert Poppe also had extensive and valuable discussions with Nzinga Broussard while on secondment at EDRI, which helped to improve the paper. Markus Frölich acknowledges support from the special research area SFB 884 of the German Science Foundation (DFG). Data and STATA do files to replicate the empirical results will be made available on request. 


\section{Introduction}

Chronic food shortage remains a serious obstacle to children's physical and cognitive development in many poor countries. Hunger diminishes children's ability to concentrate and to retain what they learn at school. School meals attempt to improve poor and credit-constrained households' investments in education by subsidizing the cost of schooling, by reducing short-term hunger and improving nutrition. In poor countries, where school enrolment is low, school meals can provide a strong incentive for poor households to send their children to school and to support their education. ${ }^{1}$ School meals appear to be attractive as they may not only increase school participation and reduce dropout, but they may also improve learning and cognitive development.

The educational benefits of a school meals programme depend on the targeting, modality and implementation of the programme. In most developing countries, school meals programmes target areas with high food insecurity, low enrolment or high gender disparity. There can be different modalities in the delivery of school meals programmes, with varied impacts. Two basic modalities widely known are: $(i)$ providing school meals on-site or (ii) as take-home rations, both of which may be combined with micronutrient supplementation (Adelman et al., 2008). While on-site meals (breakfast, lunch or snacks) are usually provided to all students, take-home rations are often given to girls only, conditional on school attendance exceeding some threshold. School meals may also involve local (community or household) contributions. Children are often involved in the acquisition of the material contributions (such as firewood) that their households are expected to make available as part of the preparation of school meals. This has a potentially detrimental effect on the learning achievement of children. Further, food 
distribution can be subject to disruption or may divert class and teacher time away from learning depending on how well the programme is implemented.

This paper examines the link between a school meals programme (SMP) in Ethiopia and its educational outcomes. It contributes to the literature by investigating the relationship between the modalities and implementation of the school meals programme (SMP) on the one hand and educational outcomes on the other. Whereas several studies have investigated the effects of school meals per se, much less is known about how school meals should be implemented and how differences in implementation affect their outcomes. In this paper, we examine variations in the implementation of SMP and how this is related to children's outcomes. While we acknowledge that the non-experimental and cross-sectional nature of the data does not allow us to fully address the problem of endogeneity, we use a unique dataset with a broad geographical coverage within Ethiopia that is likely to allow investigating the link between the SMP and educational outcomes. Other studies, e.g. Alderman et al. (2012), attain stronger internal validity but are more local in scale. Hence, while our results should not be interpreted as strong evidence of causal effects, they provide important indications about how modalities of the implementation of SMP is related to children's educational outcomes, which, as a minimum, can guide further research towards finding the optimal design of school meals programmes. The main finding in the paper is that supplementing on-site meals with take-home rations is positively associated with concentration, reading, writing and arithmetic skills. These results also suggest that not only targeted girls, but also boys benefited from the programme. The timing of the distribution of school meals is also found to play a role. Specifically, our results suggest that school meals are less effective if they are served at the end of classes, which appears to be especially important for girls. 


\section{Review of related literature}

Food deprivation remains a serious obstacle to children's physical and cognitive development in many developing countries. For example, the United Nations World Food Program (WFP) provided school meals to around 22 million children in 70 countries in 2008 (Bundy et al., 2009). SMPs are generally thought to help tackle the problem of chronic food shortages for school age children. In the short-run, school meals are expected to alleviate hunger in the classroom and help the child to concentrate better and learn more. In the long-run, improved nutrition is expected to increase children's physiological capacity for learning and to reduce morbidity by strengthening the immune system, thereby reducing missed school days due to sickness. In addition, school meals make going to school more attractive. The impact of on-site school meals on learning is expected to operate through an increase in school attendance and through improvement in learning efficiency while in school, because in the absence of hunger children are able to concentrate better and because (micronutrient-fortified) school meals may also improve cognitive functions. School meals can also subsidize the cost of school attendance by providing food with the potential of improving learning and nutrition (Adelman et al., 2008). If beneficiary households respond to school meals by reducing their food expenditures, more resources will be available, which may increase expenditures on education or other activities.

A number of studies found school meals to increase enrolment and attendance (Ahmed, 2004; Alderman et al., 2012; Buttenheim et al., 2011; Dreze and Goyal, 2003; Kazianga et al., 2012, Tan et al., 1999; Vermeersch and Kremer, 2005) where school participation has initially been low. However, effects on learning achievement and cognitive development are less clear. ${ }^{2}$ Filmer and Schady (2009) argue that students may not learn 
much due to overcrowding as a consequence of school meals attracting new students, who are often poorer. Poor marginal students may do worse in terms of learning if schools cater to elites (Duflo et al., 2008). If poor, credit-constrained households send their most promising children to school first, then the marginal students will have less favourable characteristics, e.g. in terms of ability (Card, 1999). Furthermore, on-site school meals may adversely affect the effectiveness of the educational process, if, for example, food distribution disrupts learning when school children spend time collecting firewood. In some cases the total amount of hours devoted to teaching is found to decrease by 15 percent (Vermeersch and Kremer, 2005). The environment in which school meals take place also plays an important role. If a programme increases enrolment and attendance, while teaching quality is low or teachers' absenteeism high, it is unlikely to induce better learning achievement. For example, Vermeersch and Kremer (2005) found no impact of school meals on cognitive skills; better test scores were primarily associated with greater teachers' experience. Kazianga et al. (2012) found that school meals increase enrolment but fail to improve academic performance. Finally, the school meal programme might even fail to increase nutrition if parents change their behaviour in that they provide less food at home if they know that food is provided in school, e.g. they knowing that meals are given in school they might not provide breakfast or dinner. Such substitution could possibly even lead to worse nutrition outcomes.

The evidence on the link between school meals and educational outcomes is mixed for the most part, as the review in the preceding paragraphs indicated. This has also been highlighted in a major recent review paper examining the link between school resources and educational outcome in veveloping countries covering a 20 year period (Glewwe et al., 2011), which concludes that the impact of school meals on student educational 
outcomes is inconclusive. There is also a dearth of evidence on the role played by programme implementation; and how different programme modalities may influence expected outcomes. This paper aims to contribute to the literature by providing additional evidence on the link between SMP and educational outcomes generally, and the role programme modalities and their implementation play.

\section{The School Meals Programme and the data}

\subsection{The Ethiopian School Meals Programme}

The Government of Ethiopia (GoE) adopted an Education and Training Policy in 1994 with a view to achieving the educational MDGs by the year 2015. To that end, the GoE has implemented three phases of multi-year Education Sector Development Programme (ESDP). One of the main components of the ESDP has been the SMP, which the GoE has undertaken in partnership with the United Nations World Food Program (WFP). The $3^{\text {rd }}$ phase of the ESDP expanded school meals to schools in food insecure and vulnerable areas in Ethiopia. In particular, the programme targeted pastoralist areas and chronically food deficit highland districts in the country with the aim of: attracting children to school in chronically food insecure areas, increasing enrolment, stabilizing attendance and reducing dropout. The programme also pays special attention to increasing girls' enrolment in programme areas with a view to bringing about gender parity in school enrolment.

WFP sponsored school meals started in Ethiopia in 1994 with an initial pilot project in war-affected zones in Tigray region. It has since provided school meals in chronically food insecure districts in six of the country's nine regional states (Afar, Amhara, Oromia, SNNPR, Somali and Tigray) with a particular focus on districts with lower enrolment and higher gender disparity. In 2008, WFP provided food for 915 schools 
with 482,000 children benefiting from school meals. The per child food ration consists of $150 \mathrm{gm}$ of corn-soya blend (CSB), $6 \mathrm{gm}$ of fortified vegetable oil and $3 \mathrm{gm}$ of iodized salt, provided as a cooked meal on every school day. In addition to the main programme, the WFP launched 'the Girls' Initiative' intervention in 2002 in food insecure pastoralist areas of four regional states (Afar, Somali, Oromia and SNNPR). The initiative has the objective of encouraging girls' education and narrowing the gender gap in pastoralist communities. The programme provides 8 litres of vegetable oil per semester ('take-home rations') conditional on 80 percent girl's attendance in addition to on-site school meals. In the first semester of 2010, 81,000 girls received take-home rations. The estimated cost of take-home rations is USD 8.1 per beneficiary girl (during the first semester of 2010).

In about 300 communities, WFP's school meals programme is supported by Children in Local Development (CHILD), a community-led planning tool initiated by the WFP and the Ministry of Education. CHILD is primarily intended to increase the sustainability and impact of school meals; and mainly involves capacity building for local government partners and beneficiary communities to assist communities to plan for a child-friendly school environment in order to improve the learning atmosphere. School meals may involve local contribution, which is usually in kind, with the exception of cooks' remuneration. Sometimes communities are expected to contribute labour e.g. to build canteens and storage rooms. Additionally, parents may be required to contribute firewood and water to support the preparation of meals or cash to cover payments for cooks.

\subsection{Data and descriptive analysis}

The data used in this paper come from a household survey conducted in 2010 by the World Food Program Country Office Ethiopia in partnership with the University of 
Mannheim covering school catchment areas in food-insecure districts in four of the major regions of Ethiopia (Amhara, Oromia, SNNPR and Tigray). ${ }^{3}$ Employing a twostage stratified sampling design, the survey sampled 200 school catchment areas in the four regions stratified by highland and pastoral areas. The survey covered the school catchment areas of programme schools and non-programme schools. ${ }^{4}$ The first-stage sampling was conducted using programme districts as the sampling frame for nonprogramme school catchment areas. This type of programme/non-programme school catchment area matching procedure was chosen in order to attain comparable school catchment areas. The second-stage sampling involved randomly sampling ten children aged 7 to 13 years per school catchment area using household lists irrespective of whether the children were enrolled in school at the time of the survey. ${ }^{5}$ This design feature of the survey permits a richer analysis than school based surveys since it allows investigating relationships within the school service area, thus circumventing potential selection problems stemming from focusing only on children already enrolled in schools. Only students enrolled in grades 2 to 4 were included if they were enrolled in school. In sum, the survey was restricted to (i) children aged between 7 and 13 years old and (ii) children enrolled in grades 2-4 if they were students. If a child was not enrolled, then the grade restriction did not apply, only the age restriction was effective. The survey provides information on health, education, learning, and child and household characteristics for nearly 2000 children. We dropped schools where food had not yet been distributed at the time of the survey ( 3 schools). The fact that these schools were still without food although the school year had already started is unlikely to be attributable to pure chance only. Rather, these schools might be different along unobserved characteristics. In addition, as we are interested in current school meals on current outcomes, including children in schools where food had not been distributed yet 
might understate the results. Table 1 shows the distribution of schools across regions and livelihood (highland vs. pastoralist) in the sample.

[Table 1 about here]

To measure scholastic performance, we tested children on their reading, writing and arithmetic skills. ${ }^{6}$ Children were tested regardless of whether they were enrolled in school or not. For reading, children were asked to read pre-prepared letters, words and sentences. In the writing test, children were asked to write down pre-prepared sentences that the interviewers read aloud. Children were also tested on their arithmetic skills using up to three different arithmetic questions. In all three cases, two different versions of the tests were administered depending on the age of the children involved - one set for children between the ages of 7 and 10 years and a more difficult set for children between the ages of 11 and 13 years.

To test children's cognitive development we use the Raven's Standard Progressive Matrices (SPM) test. The major benefit of this test is that no formal schooling is required to solve the questions. The nonverbal aspect of the test reduces the impact of cultural or language bias. We use a modified version of the $\mathrm{d} 2$ Test of Attention (Brickenkamp and Zillmer, 1998) to test children's concentration and attention. ${ }^{7}$ Table 2 reports child, household and school characteristics in programme and non-programme school service areas. The children's mean age is close to ten years with 68 percent of children aged 10 years or less. (10 years is the cut-off above which children were given the more difficult set of tests). Slightly more boys than girls are included in our sample. If children were enrolled, their mean grade was grade 3 . Around 20 percent of children were not enrolled in school at the time of the survey. Households in programme school service areas have slightly more children on average, have a higher share of either parents without 
education and are more often headed by a male household head. They also have a higher livestock index ${ }^{8}$ Children residing in programme school catchment areas have access to better school facilities as measured by our school equipment index. ${ }^{9}$

[Table 2 about here]

As discussed before, while there were no school meals in the non-programme schools, in the programme schools the implementation of the school feeding was not uniform. It varied in several dimensions, which we label modalities of implementation in the discussion that follows. Table 3 shows some statistics on these implementation modalities. Around a quarter of schools have the additional programme component: take-home rations. Almost 50 percent of the schools have implemented the communityled planning tool (CHILD). Schools usually establish food management committees as part of the programme to oversee delivery, storage and distribution of food. In 59 percent of cases the food management committee has been trained to enable members to more effectively assume their responsibilities. In 43 percent of cases cooks have been trained. On the other hand, 88 percent of schools reported that they experienced disruptions in the distribution of food and water. 16 percent reported that cooks' absenteeism was the main reason for the disruption. In the majority of schools, food is distributed half-way through the school day, and only 25 percent of the schools use a special eating place within the school compound. Most schools use a traditional threestone fire place for cooking and reported inadequate storage facilities. The mean programme duration at the time of data collection is 8.43 years.

[Table 3 about here]

Table 4 reports households' contributions to the programme. 6 percent of beneficiary households are member of a food management committee. Their most important 
contribution to school meals is firewood, followed by cash and water contribution. Only 2 percent of beneficiary households report no contribution at all.

[Table 4 about here]

\section{Empirical framework}

\subsection{Empirical specification}

The paper examines the link between, on the one hand, school meals, its modalities of programme implementation and, on the other, cognitive skills, concentration span, reading, writing, arithmetic and children's activities as outcomes. These outcomes are correlated with school, teacher, household or child characteristics, many of which are not observed. The empirical analysis is split into two parts: In Section 4.2 we compare programme versus non-programme school catchment areas, controlling for a number of characteristics $(\mathbf{X})$. In this analysis, school meals status is considered as binary and we thus compare SMP versus non-SMP pupils. Thereafter in Section 4.3 we examine the effects of the different modalities of implementation, controlling for the same covariates X. This analysis relies only on the subsample of programme school catchment areas. In both sections we use a linear regression model of the following form:

$$
y_{i s}=\mathbf{X}_{i s} \alpha+D_{s}^{\prime} \delta+\varepsilon_{i s}
$$

where $i$ and $s$ denote a child and school service area, $y$ represents the outcome of interest and $\mathbf{X}$ is a vector of child, household, and school service area characteristics, and $\epsilon$ denotes the error term. ${ }^{10}$ For the analysis in section 4.2 , the variable variable $\boldsymbol{D}$ is a binary variable for programme status, i.e. SMP school or non-SMP school. On the other hand, for the analysis in Section $4.3, \boldsymbol{D}$ is a vector that captures the characteristics and modalities of programme implementation. 
In Section 4.2 we report results using OLS and propensity score matching in order to analyse sensitivity to functional form and estimation specification. In Section 4.3 we will use only OLS, since there $\boldsymbol{D}$ represents a non-binary vector of programme modalities, which themselves are correlated and thus require joint estimation of their effects. ${ }^{11}$

In all empirical analyses, the vector $\mathbf{X}$ always includes the following control variables: the child's age, a dummy for the child being aged between 7 and 10 years, ${ }^{12}$ the child's gender, a dichotomous variable whether the head of household is male, the number of children in the household, a dichotomous variable whether both parents are uneducated, the logarithm of total household expenditures, the school equipment index, a dichotomous variable whether the district of the school catchment area is characterised by pastoralism, and controls for the region (Amhara, Oromia, SNNPR and Tigray). (Obviously, control variables without variation were dropped in the respective analyses; e.g. in the subgroup analysis for girls or boys we did not include child gender in $\mathbf{X}$.)

\subsection{Empirical results - programme versus non-programme schools}

In this subsection, we compare programme to non-programme schools and we therefore use the full sample that includes both programme and non-programme (comparison) school catchment areas. Table 5 reports OLS and Propensity Score Matching (PSM) based results for the educational outcomes (reading, writing, math and concentration), separately for the subsamples of boys and girls, controlling for the binary school meal indicator and other controls. Cluster robust standard errors are used throughout for the OLS regressions. The propensity score matching regressions, which uses'psmatch2' (Leuven and Sianesi 2010), estimates the Average Treatment Effect on the Treated (ATT). ${ }^{12}$ Figure 1 depicts histograms showing the distribution of propensity scores for the 'untreated' and 'treated' pupils, with a good overlap between the two gropus overall. 
The results obtained are robust to alternative bandwidth choices. We also implemented direct matching using the 'nplate' (Frölich 2007), which delivers broadly similar results. In both cases, bootstrap standard errors with clusters at the primary sampling unit of school catchment area have been used.

[Figure 1 about here]

Tables A.2 to A.5 in the Appendix report further estimates for the different outcomes: Table A.2 gives estimates stratified by age group. Table A.3 provides estimates on child labour activities while Tables A.4 and A.5 show estimates on child labour activities by household asset ownership. Most of these estimates are insignificant. Thus, even though the OLS and PSM estimates reported go in the same direction and are not statistically different from each other in most cases, their insignificance makes it difficult to draw strong conclusions. The most stable estimates found relate to child labour activities, which are reported in Appendix Tables A.4 and A.5. In the subsample of low-asset households, it is found that school meals are associated with higher child labour, i.e. more domestic tasks and some evidence (in Appendix Table A.3) of more work in the family business for boys, while on the other hand paid work seems to be lower for younger age cohorts. On the other hand, no such association is found for children in high-asset households (Appendix Table A.5). Regarding cognitive outcomes (Tables 5 and Appendix Table A.2), most estimates are negative but not significantly different from zero. Only the estimates for concentration seem to be negatively associated with school meals, although not in every specification estimated. Table 6 provides sensitivity analysis on the estimates for boys and girls using additional matching algorithms. The results obtained are not found to be sensitive to the type of matching algorithm used. Overall, the estimated associations between school meals and child outcomes tend to be 
negative (more labour, less concentration skills), but, as mentioned earlier, we would rather abstain from interpreting these estimates as causal effects. This is because of concerns that the actual selection process into the school meals programme might have also been affected by unobservables that are not fully captured in our control variables. In this respect, the lack of information on prior pupil attainment and school management are worth emphasizing in particular.

[Tables 5 and 6 about here]

\subsection{Programme implementation modalities}

The analysis in this section focuses on programme implementation modalities, thus comparing only treatment schools with different implementation modalities of the treatment. This design structure is likely to make the problem of selection less of a concern since whether school meals are served in the morning or during lunch or whether cooks have been trained or not, among others, may depend less on unobservables than whether a school was selected for SMP or not. One cannot completely rule out the possibility of systematic differences in unobservables however, especially given the lack of information on school management practices that we do not observe in the data. Still, this design is likely to render systematic variations in unobservables less important in explaining variations in the modalities vis-à-vis the earlier design, which compares programme and non-programme schools. Tables 7 and 8 report estimates relating to programme modalities. The results reveal more systematic patterns than those reported in the preceding subsection. They may also be less prone to problems of endogeneity in comparison given that some of the unobserved characteristics (such as prior attainment) are less likely to play a substantial role in this case. 
As pointed earlier, the analysis on programme modalities uses the subsample of programme schools. The implementation characteristics $\boldsymbol{D}$ included in the regressions are: (i) whether CHILD is implemented, (ii) whether take-home rations are distributed, (iii) whether the food management committee is trained, (iv) whether the cooks are trained, $(v)$ whether the school had at least one day of food not being distributed, (vi) whether food is served half-way through classes, (vii) whether food is served at the end of classes (serving food at the beginning of classes is the reference category), (viii) the duration of the programme, (ix) whether households contribute to the programme with cash, and $(x)$ whether households contribute with material (defined as labour, water or firewood contributions), the reference category being no contribution. We use means at the school catchment area level for the contribution-related variables to reduce potential measurement errors at the household level and to avoid potential confounding with individual household income. The modality and implementation variables are included simultaneously in the estimations.

Because the way the school feeding is implemented is characterised by many variables, which need to be included in the same regression as they are all likely to be correlated, we only report results from OLS. This is because the implementation modality is a type of treatment vector and no longer a binary indicator with some variables measured continuously (e.g. the duration of school meal programme), which makes the binary propensity score no longer applicable. However, we also examined PSM for a sub-vector of the implementation modalities. The results obtained are mostly in line with those from OLS though they are noisy given that observations are very small in each cell of the combined treatment modalities. 
The estimation results for each modality and implementation characteristics, which are reported separately by gender (Table 7) and age (Table 8) are discussed in the following paragraphs.

[Table 7 and Table 8 about here]

(i) Children in Local Development (CHILD): For the CHILD component no significant result is found for boys, but for girls a positive association is found for cognitive skills with a magnitude of 1.4 points $($ s.e. $=0.51) .{ }^{13}$ Girls are found to be 11.6 percentage points (s.e. $=5.7 \%$ ), or a quarter of a standard deviation, more likely to read a sentence if the CHILD component is in place.

(ii) Take-home rations: take-home rations are found to increase girls' concentration score by 78.1 points $($ s.e. $=23.8$ ), or by about 1.4 standard deviations. This estimate is particularly large in terms of economic significance. Take-home rations supplement onsite school meals in pastoralist and semi pastoralist areas. They are aimed at improving girls' attendance in areas that have lower girls' school attendance rates. Take-home rations' association with reading is found to be substantial with girls 21.9 percentage points $($ s.e. $=9.7 \%$ ) more likely to read a sentence. Similarly, girls on take-home rations are found to be 47.5 percentage points (s.e. $=17.6 \%$ ) more likely to write, an increase by about 1 standard deviation. Take-home rations are also found to be positively associated with reading skills for boys, both in terms of reading a word and a sentence. This finding is quite remarkable as take-home rations are conditional on girls' attendance. Nevertheless, boys may also be benefiting from take-home rations due to the value transfer to the household, which seems to improve boys' attendance and their nutritional status. Take-home rations are also found to be positively associated with writing and arithmetic skills for boys. The results obtained also reveal that take-home rations are 
positively associated with concentration for younger children generally, as well as improving reading for older children and writing for both younger and older children. Overall, take-home rations appear to have the largest and most stable positive association than any of the other modality and implementation characteristics.

(iii) Training of food management committee: No significant link of training of the food management committee is found both for boys and girls. For older children some positive association is found for cognitive skills and math outcomes.

(iv) Training of cooks: while many of the estimates are insignificant, they are positive throughout; and some significant link is found vis-à-vis cognitive skills and concentration outcomes for boys and girls and for the younger age cohort.

(v) Disruption in food distribution: most of the estimates are insignificant, while the significant ones are found to be inconclusive being partly positive and partly negative.

(vi) The timing of food served: serving food half-way or at the end of the school day is found to be less favourable than serving food at the beginning of the school day (which is the reference category) for girls. Particularly for serving food at the end of the school day, as opposed to serving food in the morning, negative estimates are found for cognitive development, reading skills (of both reading a word and a sentence), and arithmetic skills. These results appear to be the strongest and most stable across all variables in Table 7, next to take home rations. These findings underline the importance of serving food at the beginning of the school day, as school meals, through hunger alleviation during school hours, are expected to improve children's concentration. In addition, serving food at the end of classes may crowd out food served at home. Serving food later in the school day is found to be negatively associated with most outcomes for girls in particular. 
(vii) Programme duration: We find a longer programme duration being positively associated with concentration for boys, where an additional year on the programme is found to increase the concentration score by 6 points $($ s.e. $=1.9) .{ }^{15} \mathrm{We}$ also find a longer programme duration being positively correlated with cognitive development for girls, an additional year increases the Raven's test score by 0.1 points $(\mathrm{s} . \mathrm{e} .=0.06)$. These findings appear to suggest that a school meals programme functions better, the longer its implementation lasts. On the other hand, most other estimates are insignificant and small; so no strong conclusion may be drawn.

(viii) Household contributions: firewood, water, labour and cash, which is usually contributed towards the cooks' remuneration, are included in the materials category (the reference category is no contribution at all). To avoid potential measurement errors at the household level and potential confounding with individual household income, school catchment area level averages of the contributions have been used. Generally, household contributions can be detrimental to schooling outcomes, particularly if the burden of the contribution falls on the children themselves. On the other hand, household contributions may also improve the availability of resources that are complementary to the distribution of food, thereby reinforcing any beneficial influences school meals have. Making any kind of contribution (cash or material), as opposed to no contribution, is found to be negatively associated with writing skills for boys. In addition, cash contributions, as opposed to no contribution at all, appear to improve reading skills for girls. Cash contributions are found to be positively associated with concentration for younger children but negatively associated with their writing skills. On the other hand, they appear to be correlated positively with reading and arithmetic skills for older children. Overall, however, the results linked to household contributions appear to be largely inconclusive to lead to any strong conclusion. 


\section{Conclusion}

The effectiveness of school meal programmes depends on how well the programmes are designed in terms of modality as well as how well they are implemented. However, little is known about the role of school meals programme modalities and their implementation on generating learning achievement and enhancing cognitive development. This paper investigated the role of the Ethiopian school meals programme, its modalities and implementation on learning outcomes, cognitive development and attention span in rural areas of the country.

Two main results stand out: first, most of the implementation characteristics do not appear to matter much. This is mainly because the links found being not strong and systematic enough to yield coherent patterns across the different learning outcomes considered, rather than due to having no link whatsoever. On the other hand, two programme characteristics stand out. Take-home rations and serving food early in the morning are found to be important and show the most systematic patterns across all the estimates. Supplementing on-site meals with take-home rations is found to be positively associated with concentration, reading, writing and arithmetic skills. The results obtained also given some evidence that take-home rations benefit not only girls targeted by the programme, but also all children in beneficiary households. This may be due to the value transfer to members of benefiting households, which is likely to improve children's nutritional status and school attendance. This finding is in line with Kazianga et al. (2014) and Fafchamps et al. (2008).

Our results also suggest that school meals are less effective if they are served at the end of classes, which appears to be the case especially for girls. School meals should be served in the morning in order to alleviate hunger and thus improve children's 
concentration. In addition, serving food at the end of classes may crowd out food served at home.

The paper is innovative in the way it used rich data from a household survey with a complex design and in its analysis of programme implementation modalities as well as the various children learning outcome considered. These are features that are likely to be improvements on previous studies that are largely based on school surveys. On the other hand, the reliance on household surveys meant that the study lacked detailed information on school management practices and pupil (and school-level) prior attainment, which are widely reported to be key determinants of children's' learning outcome, and hence the influence school meals programmes may have in determining child outcomes. Given this, the results reported in the paper, which provide tentative insights into potential improvements that can be introduced to school meal programmes, may have to be read cautiously. 


\section{References}

Adelman, S. W., Gilligan, D. O., \& Lehrer, K. (2008). How effective are food for education programmes? A critical assessment of the evidence from developing countries. Food Policy Review 9. Washington, D.C.: International Food Policy Research Institute.

Ahmed, A. U. (2004). Impact of feeding children in school: Evidence from Bangladesh. Report commissioned by the United Nations University. Washington, D.C.: International Food Policy Research Institute.

Alderman, H., Gilligan, D. O., and Lehrer, K. (2012). The impact of food for education programmes on school participation in Northern Uganda. Economic Development and Cultural Change, 61(1), 187-218.

Behrman, J. R., Parker, S. W., \& Todd, P. E. (2009). Medium-term impacts of the Oportunidades conditional cash-transfer programme on rural youth in Mexico. In S. Klasen, \& F. Nowak-Lehmann (Eds.). Poverty, inequality, and policy in Latin America. CESifo Seminar Series (pp. 219-270). Cambridge, MA and London, UK: MIT Press.

Brickenkamp, R. \& Zillmer, E. (1998). The d2 Test of Attention. Seattle, WA: Hogrefe and Huber, 1. US edition.

Bundy, D., Burbano, C., Grosh, M., Gelli, A., Jukes, M., \& Drake, L. (2009). Rethinking school feeding: Social safety nets, child development, and the education sector. Washington, D.C.: World Bank.

Card, D. (1999). The causal effect of education on earnings. In O. Ashenfelter \& D. Card (Eds.). Handbook of labor economics (Volume 3A, pp. 1801-1863). Amsterdam, the Netherlands, New York, NY, and Oxford, UK: Elsevier Science, North-Holland.

Dreze, J. \& Goyal, A. (2003). Future of mid-day meals. Economic and Political Weekly, 38(44), 4673-4683. 
Duflo, E., Dupas, P., \& Kremer, M. (2008). Peer effects, teacher incentives, and the impact of tracking: Evidence from a randomized evaluation in Kenya. Working Paper 14475. Cambridge, MA: National Bureau of Economic Research.

Fafchamps, M., Kebede, B. and Quisumbing, A. (2008). Intrahousehold welfare in rural Ethiopia. Oxford Bulletin of Economics and Statistics, 71(4), 567-599.

Filmer, D. \& Schady, N. (2009). School enrollment, selection and test scores. Policy Research Working Paper 4998. Washington, D.C: World Bank.

Frölich, M. (2007): Nonparametric IV estimation of local average treatment effects with covariates, Journal of Econometrics, 139, 35-75.

Gewa, C., Weiss, R., Bwibo, N., Whaley, S., Sigman, M., Murphy, S., Harrison, G., \& Neumann, C. (2009). Dietary micronutrients are associated with higher cognitive function gains among primary school children in rural Kenya. British Journal of Nutrition, 101, 1378-1387.

Glewwe, P., Hanushek, E., Humepage, S. and Ravina, R. (2011). School Resources And Educational Outcomes in Developing Countries: A Review of The Literature From 1990 to 2010. NBER Working Paper Series, Working Paper 17554, NBER, Cambridge, MA.

Haile, G., Poppe, R., \& Frölich, M. (2011). School meals programme in Ethiopia: A mixedmethods based impact study. Final Evaluation Report. Addis Ababa, Ethiopia: United Nations World Food Program.

Kazianga, H., de Walque, D., and Alderman, H. (2012). Educational and child labour impacts of two Food-for-Education schemes: Evidence from a randomised trial in rural Burkina Faso. Journal of African Economies, 21(5), 723-760. 
Kazianga, H., de Walque, D., and Alderman, H. (2014). School feeding programmes, intrahousehold allocation and the nutrition of siblings: Evidence from a randomized trial in rural Burkina Faso. Journal of Development Economics, 106, 15-34.

Leuven, E. \& Sianesi, B. (2010). Psmatch2, retrieved from http://leuven.economists.nl.

Miguel, E. \& Kremer, M. (2004). Worms: Identifying impacts on education and health in the presence of treatment externalities. Econometrica, 72(1), 159-217.

Poppe, R. (2014). Poor eyesight and educational outcomes in Ethiopia. The Review of Black Political Economy, 41(2), 205-223.

Tan, J.-P., Lane, J., \& Lassibille, G. (1999). Student outcomes in Philippine elementary schools: An evaluation of four experiments. World Bank Economic Review, 13(3), 493-508.

Vermeersch, C. \& Kremer, M. (2005). School meals, educational achievement, and school competition: Evidence from a randomized evaluation. Policy Research Working Paper 3523. Washington, D.C: World Bank.

Whaley, S., Sigman, M., Neumann, C., Bwibo, N., Guthrie, D., Weiss, R., Alber, S., \& Murphy, S. (2003). The impact of dietary intervention on the cognitive development of Kenyan school children. The Journal of Nutrition, 133, 3965-3971. 


\section{Notes}

${ }^{1}$ Other interventions to attract children to school that have been found to increase school enrollment and attendance include deworming (Miguel and Kremer, 2004), provision of additional teachers (Duflo et al., 2008) and conditional cash transfers (Behrman et al., 2009).

${ }^{2} \mathrm{~A}$ body of literature investigates the impact of school meals on (short-term) cognitive development, focusing on the specific micronutrient content of school meals. Although the empirical evidence is mixed, there appears to be a consensus on the importance of animal source food. For example, Whaley et al. (2003) explore the effect of three different diets (meat, milk, and energy), suggesting that animal source food has greater impact on cognitive function. Similarly, Gewa et al. (2009) investigate the effect of different school meals comprised of exclusively vegetarian meals, milk, or supplemented with meat; results show that the meat variant is relatively more important in terms of improving cognitive function among school-age children. However, most of these studies are conducted in a laboratory setting, which limits their external validity.

${ }^{3}$ The Afar and Somali regional states were not included in the surveys due to security and logistical challenges at the time.

${ }^{4}$ In Tigray and Amhara WFP's school meals programme is operational in highland areas only. Additionally, there was a smaller subsample of phased-out programme school areas, i.e. of schools which had received meals only in the past but not now. These schools are not included in the analyses of this paper since the information on the timing and modalities of the school meals programme was rather scarce. Furthermore, in this paper we focus on the link between current school meals and learning outcomes. For phased-out schools the treatment status is imprecise since some children might have received some meals in the past but there is no precise measurement of such partial treatment status and its timing.

${ }^{5}$ For a more detailed description of the survey design see Haile et al. (2011). 
${ }^{6}$ The survey adapted tests on reading, writing and arithmetic skills from the Young Lives project, a longitudinal study conducted in four countries (Peru, Ethiopia, India and Vietnam). http://www.younglives.org.uk.

${ }^{7}$ For a description of the test design see Poppe (2014).

${ }^{8}$ The livestock index is a weighted index using tropical livestock units (TLU) as weights as follows: cattle are weighted by 0.7 TLU, donkeys or horses are weighted by 0.3 TLU, goats or sheep are weighted by 0.15 TLU and poultry are weighted by 0.05 TLU.

${ }^{9}$ This index is defined as the sum (range 0-4) of whether sanitation facilities are available, school buildings are in a good condition, the school compound is fenced and classrooms have glass windows.

${ }^{10}$ Robust standard errors are used to adjust for school catchment area cluster.

${ }^{11}$ In an earlier version of the paper we had also estimated random-effects models where random school service area effects were included in the linear model. Overall, the main results were similar with, as expected, somewhat larger precision. Due to space constraints, these estimates are not reported here.

${ }^{12}$ We use normal kernel, with logit specification of the propensity score and the inbuilt bandwidth-choice algorithms.

\begin{abstract}
${ }^{13}$ In the regressions, we control for whether a child is aged between 7 and 10 years because the survey administered different tests for younger and older children - except for the Raven's test and the concentration test which were administered irrespective of age - as in small samples the distribution of younger children might be unequal across programme status.
\end{abstract}

\footnotetext{
${ }^{14} \mathrm{We}$ also used the random-effects model. Because the random-effects model produces similar results, only results from OLS and PSM are presented.
} 
${ }^{15}$ In the sample of programme school catchment area girls, the score has a mean of 12.8 and a standard deviation of 3.5. See Table A.1 in the Appendix.

${ }^{16}$ Note that no effects for concentration are reported because the regressor Disruption in food distribution dropping from the regression. This happened because, for budget reasons, the concentration test had been collected only in a subset of school service areas only. It happened that disruptions had always occurred the particular subset of schools, thus with no variation in the subset of schools where the concentration outcome had been collected.

${ }^{17}$ In the sample of programme school catchment area boys, the score has a mean of 136.7 and a standard deviation of 56.6. See Table A.1 in the Appendix. 
Table 1: Distribution of schools, by region and livelihood

\begin{tabular}{lccc}
\hline & Programme & Non-programme & Total \\
\hline Amhara highland & 14 & 17 & 31 \\
Oromia highland & 14 & 14 & 28 \\
Oromia pastoralist & 12 & 13 & 25 \\
Tigray highland & 14 & 16 & 30 \\
SNNPR highland & 10 & 12 & 22 \\
SNNPR pastoralist & 5 & 5 & 10 \\
Subtotal highland & 52 & 59 & 111 \\
Subtotal pastoralist & 17 & 18 & 35 \\
Total & 69 & 77 & 146 \\
\hline
\end{tabular}

Notes: SNNPR refers to Southern Nations, Nationalities and Peoples' Region.

Table 2: Summary statistics (means) of selected characteristics of children, households, and schools

\begin{tabular}{lccc}
\hline \multicolumn{1}{c}{ Variable Names } & Programme & Non- & p-value \\
\hline Child characteristics & & & \\
Age & 9.96 & 9.91 & .66 \\
Children aged $\leq 10$ & .68 & .68 & .9 \\
Male & .56 & .52 & .19 \\
Grade & 2.98 & 3 & .64 \\
Enrolled in school & .79 & .8 & .45 \\
Household characteristics & & & \\
Number of children & 4.08 & 3.85 & .01 \\
Total expenditures (log) & 5.82 & 5.82 & .93 \\
Neither parent attended school & .68 & .58 & .0 \\
Male headed household & .89 & .83 & .0 \\
Livestock index & 3.89 & 3.08 & .01 \\
School characteristics & & & \\
School equipment index & 2.43 & 2.13 & .0 \\
Highland area & .75 & .76 & .61 \\
\hline
\end{tabular}

Notes: The p-value stems from a means comparing t-test. The livestock index is a weighted index using tropical livestock units (TLU) as weights as follows: cattle are weighted by 0.7 TLU, donkeys or horses are weighted by $0.3 \mathrm{TLU}$, goats or sheep are weighted by $0.15 \mathrm{TLU}$ and poultry are weighted by 0.05 TLU. The school equipment index is defined as the sum (range 0-4) of whether sanitation facilities are available, school buildings are in a good condition, the school compound is fenced and classrooms have glass windows. 
Table 3: Summary statistics on school meals programme modality and implementation

\begin{tabular}{lc}
\hline \hline \multicolumn{1}{c}{ Variable Names } & Mean \\
\hline Modality of school meal programme & .26 \\
Take-home rations given & .48 \\
Children in Local Development (CHILD) & \\
Timing of food distribution: & .34 \\
Given at beginning of school day & .62 \\
Half-way through & .04 \\
Given at end of school day &
\end{tabular}

Implementation of school meals

Food management committee trained $\quad .59$

Cooks trained $\quad .43$

Disruption in food distribution (yes=1) $\quad .88$

Reasons for days without food

No food $\quad .25$

No water $\quad .28$

No fuel $\quad .03$

Cooks were absent $\quad .16$

Other reason $\quad .28$

Facilities

Three-stone fire place $\quad .85$

Improved stove $\quad .15$

Storage facility adequate/safe $\quad .87$

Special eating place in school $\quad .25$

Programme duration (years) $\quad 8.43$

Number of observations (schools) 69 
Table 4: Summary statistics on households' involvement and contribution

\begin{tabular}{lc}
\hline \multicolumn{1}{c}{ Variable Names } & Mean \\
\hline Households' involvement & \\
Member of food management committee & .06 \\
& \\
Households' contribution & .02 \\
No contribution & .35 \\
Cash & .49 \\
Firewood & .03 \\
Labour & .09 \\
Water & .61 \\
Firewood, labour, or water & \\
& 688 \\
\hline
\end{tabular}

Figure 1: Histograms of propensity score for the treated and untreated.

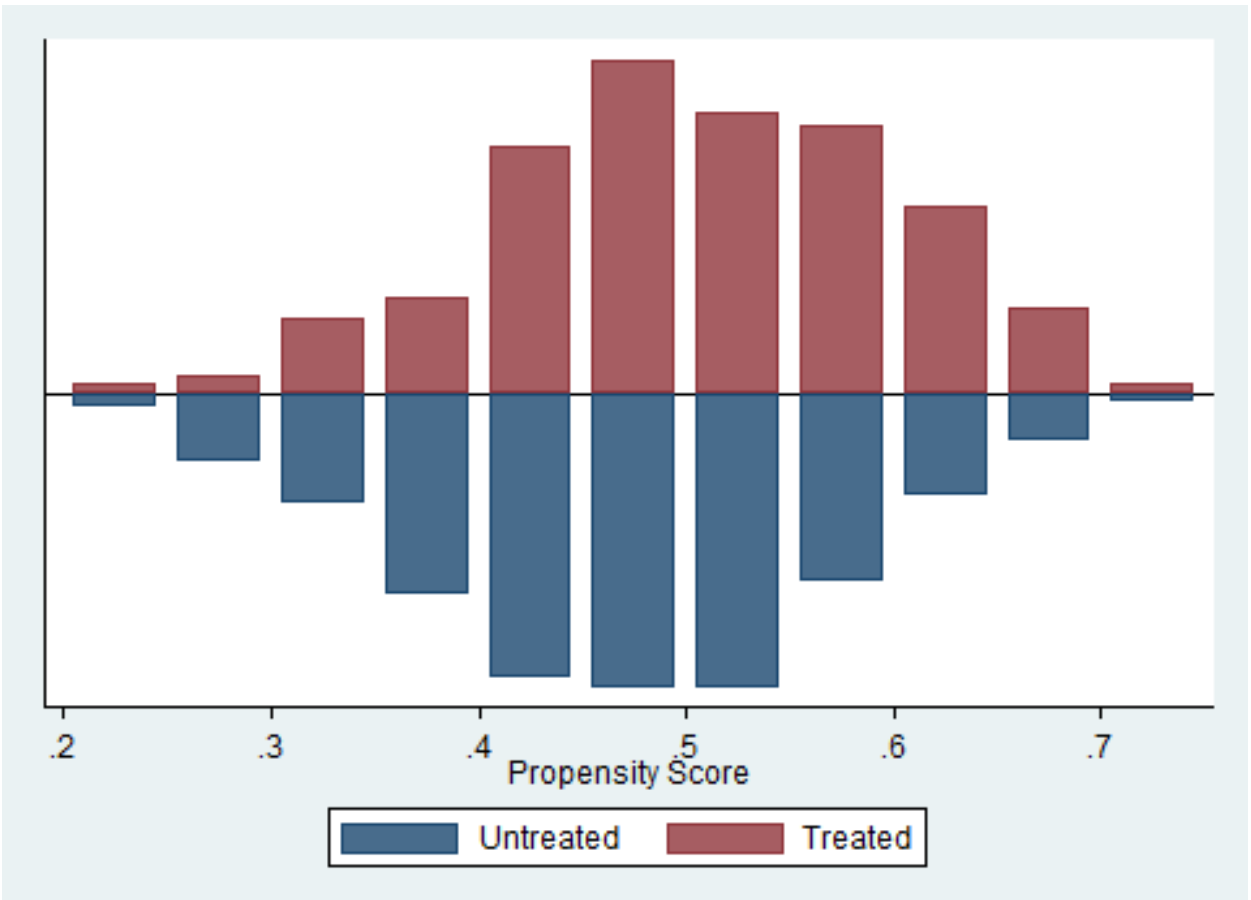


Table 5: OLS and matching based estimates: cognitive skills, concentration and learning achievements - by gender

\begin{tabular}{|c|c|c|c|c|c|c|}
\hline & $\begin{array}{c}(1) \\
\text { Raven's } \\
\text { test }\end{array}$ & $\begin{array}{c}(2) \\
\text { Concentrati } \\
\text { on }\end{array}$ & $\begin{array}{l}(3) \\
\text { Reads } \\
\text { words }\end{array}$ & $\begin{array}{c}(4) \\
\text { Reads } \\
\text { sentences }\end{array}$ & $\begin{array}{c}(5) \\
\text { Writes }\end{array}$ & $\begin{array}{l}(6) \\
\text { Math }\end{array}$ \\
\hline \multicolumn{7}{|c|}{ Boys } \\
\hline \multicolumn{7}{|l|}{$O L S$} \\
\hline Coefficient & -0.324 & $-13.507^{*}$ & -0.02 & -0.007 & -0.016 & -0.052 \\
\hline Std. error & $(0.351)$ & (7.914) & (0.039) & $(0.038)$ & $(0.037)$ & $(0.035)$ \\
\hline Observations & 689 & 300 & 725 & 725 & 725 & 723 \\
\hline \multicolumn{7}{|l|}{ Matching } \\
\hline ATT & -0.374 & $-16.536^{*}$ & -0.029 & -0.013 & -0.028 & -0.040 \\
\hline Std. error & $(0.360)$ & $(8.760)$ & $(0.047)$ & $(0.046)$ & $(0.044)$ & $(0.042)$ \\
\hline Observations & 689 & 300 & 725 & 725 & 725 & 723 \\
\hline \multicolumn{7}{|c|}{ Girls } \\
\hline \multicolumn{7}{|l|}{$O L S$} \\
\hline Coefficient & 0.005 & -12.911 & -0.048 & -0.05 & $-0.071 *$ & -0.034 \\
\hline Std. error & $(0.372)$ & (8.559) & $(0.038)$ & $(0.035)$ & $(0.041)$ & $(0.041)$ \\
\hline Observations & 588 & 264 & 635 & 635 & 635 & 635 \\
\hline \multicolumn{7}{|l|}{ Matching } \\
\hline ATT & -0.031 & -12.188 & -0.079 & -0.073 & -0.089 & -0.043 \\
\hline Std. error & $(0.424)$ & (10.209) & (0.049) & $(0.049)$ & $(0.054)$ & $(0.048)$ \\
\hline Observations & 588 & 264 & 635 & 635 & 635 & 635 \\
\hline
\end{tabular}


Table 6: Matching based sensitivity analysis: cognitive skills, concentration and learning achievement - by gender

\begin{tabular}{|c|c|c|c|c|c|c|}
\hline & $\begin{array}{l}(1) \\
\text { Raven's } \\
\text { test }\end{array}$ & $\begin{array}{c}(2) \\
\text { Concentration }\end{array}$ & $\begin{array}{l}(3) \\
\text { Reads } \\
\text { words }\end{array}$ & $\begin{array}{c}(4) \\
\text { Reads } \\
\text { sentences }\end{array}$ & $\begin{array}{c}(5) \\
\text { Writes }\end{array}$ & $\begin{array}{l}\text { (6) } \\
\text { Math }\end{array}$ \\
\hline \multicolumn{7}{|c|}{ Boys } \\
\hline \multicolumn{7}{|c|}{ Matching using one nearest neighbour } \\
\hline ATT & -0.05 & $-20.209^{*}$ & 0.023 & 0.04 & -0.055 & -0.029 \\
\hline Std. error & $(0.421)$ & $(11.134)$ & $(0.052)$ & $(0.054)$ & $(0.052)$ & $(0.056)$ \\
\hline Observations & 689 & 300 & 725 & 725 & 725 & 723 \\
\hline \multicolumn{7}{|c|}{ Matching using two nearest neighbours } \\
\hline ATT & -0.074 & $-19.507^{*}$ & 0.009 & 0.011 & -0.042 & -0.046 \\
\hline Std. error & $(0.401)$ & $(11.253)$ & $(0.054)$ & $(0.055)$ & $(0.053)$ & $(0.054)$ \\
\hline Observations & 689 & 300 & 725 & 725 & 725 & 723 \\
\hline \multicolumn{7}{|c|}{ Matching using local linear regression } \\
\hline ATT & -0.218 & $-17.107 * * *$ & -0.016 & -0.011 & -0.03 & -0.037 \\
\hline Std. error & $(0.351)$ & (7.49) & $(0.047)$ & $(0.045)$ & $(0.045)$ & $(0.044)$ \\
\hline Observations & 689 & 300 & 725 & 725 & 725 & 723 \\
\hline \multicolumn{7}{|c|}{ Girls } \\
\hline \multicolumn{7}{|c|}{ Matching using one nearest neighbour } \\
\hline ATT & 0.16 & -13.473 & -0.055 & -0.083 & $-0.117 *$ & -0.055 \\
\hline Std. error & $(0.535)$ & (11.177) & $(0.06)$ & $(0.056)$ & $(0.065)$ & $(0.062)$ \\
\hline Observations & 588 & 264 & 635 & 635 & 635 & 635 \\
\hline \multicolumn{7}{|c|}{ Matching using two nearest neighbours } \\
\hline ATT & -0.312 & -8.714 & -0.041 & -0.084 & $-0.103 *$ & -0.069 \\
\hline Std. error & $(0.528)$ & (11.597) & $(0.059)$ & $(0.056)$ & $(0.062)$ & $(0.056)$ \\
\hline Observations & 588 & 264 & 635 & 635 & 635 & 635 \\
\hline \multicolumn{7}{|c|}{ Matching using local linear regression } \\
\hline ATT & 0.105 & -8.336 & -0.068 & -0.071 & -0.078 & -0.058 \\
\hline Std. error & $(0.414)$ & (10.719) & $(0.05)$ & $(0.048)$ & $(0.057)$ & $(0.046)$ \\
\hline Observations & 588 & 264 & 635 & 635 & 635 & 635 \\
\hline
\end{tabular}


Table 7: School meals programme modalities and learning outcomes, by gender

\begin{tabular}{|c|c|c|c|c|c|c|}
\hline & $\begin{array}{c}(1) \\
\text { Raven's } \\
\text { test }\end{array}$ & $\begin{array}{c}(2) \\
\text { Concentrati } \\
\text { on }\end{array}$ & $\begin{array}{c}(3) \\
\text { Reads } \\
\text { words }\end{array}$ & $\begin{array}{c}\text { (4) } \\
\text { Reads } \\
\text { sentences }\end{array}$ & $\begin{array}{c}(5) \\
\text { Writes }\end{array}$ & $\begin{array}{c}(6) \\
\text { Math }\end{array}$ \\
\hline \multicolumn{7}{|c|}{ Boys } \\
\hline \multirow[t]{2}{*}{ CHILD component } & -0.150 & -32.664 & -0.104 & -0.071 & -0.010 & -0.042 \\
\hline & $(0.585)$ & $(25.422)$ & $(0.081)$ & $(0.072)$ & $(0.083)$ & $(0.073)$ \\
\hline \multirow[t]{2}{*}{ Take-home rations } & -1.307 & -5.979 & $0.201 *$ & $0.517 * * *$ & $0.520 * * *$ & $0.318 * *$ \\
\hline & $(1.028)$ & $(20.553)$ & $(0.114)$ & $(0.112)$ & $(0.130)$ & $(0.121)$ \\
\hline \multirow[t]{2}{*}{ Food management committee trained } & 0.465 & -8.824 & 0.010 & -0.080 & 0.021 & -0.013 \\
\hline & $(0.534)$ & $(10.362)$ & $(0.055)$ & $(0.060)$ & $(0.065)$ & $(0.061)$ \\
\hline \multirow[t]{2}{*}{ Cooks trained } & 0.897 & $19.078 *$ & 0.012 & 0.059 & 0.089 & 0.062 \\
\hline & $(0.547)$ & $(10.505)$ & $(0.054)$ & $(0.057)$ & $(0.064)$ & $(0.052)$ \\
\hline \multirow[t]{2}{*}{ Disruption in food distribution } & 0.952 & - & 0.026 & 0.055 & -0.021 & 0.050 \\
\hline & $(0.797)$ & - & $(0.080)$ & $(0.073)$ & $(0.084)$ & $(0.103)$ \\
\hline \multirow[t]{2}{*}{ Meals served at half-way } & -0.406 & 4.401 & -0.044 & -0.046 & -0.049 & 0.020 \\
\hline & $(0.473)$ & $(15.498)$ & $(0.073)$ & $(0.060)$ & $(0.083)$ & $(0.065)$ \\
\hline \multirow[t]{2}{*}{ Meals served at end of school day } & -0.645 & -15.491 & 0.005 & -0.064 & -0.234 & -0.117 \\
\hline & $(0.707)$ & $(24.253)$ & $(0.178)$ & $(0.190)$ & $(0.205)$ & $(0.161)$ \\
\hline \multirow[t]{2}{*}{ School meals programme duration } & 0.024 & $6.021 * * *$ & -0.004 & -0.001 & 0.002 & -0.005 \\
\hline & $(0.074)$ & $(1.945)$ & $(0.008)$ & $(0.008)$ & $(0.009)$ & $(0.008)$ \\
\hline \multirow[t]{2}{*}{ Cash contribution } & 3.258 & 82.131 & 0.717 & -0.086 & $-1.224 * * *$ & -0.151 \\
\hline & $(4.280)$ & $(67.714)$ & $(0.572)$ & $(0.557)$ & $(0.424)$ & $(0.420)$ \\
\hline \multirow[t]{2}{*}{ Material contribution } & -0.678 & 74.192 & 0.422 & -0.403 & $-1.202 * * *$ & -0.300 \\
\hline & $(4.360)$ & $(70.951)$ & $(0.585)$ & $(0.567)$ & $(0.405)$ & $(0.428)$ \\
\hline \multirow[t]{2}{*}{$\mathrm{N}$} & 322 & 148 & 333 & 333 & 333 & 332 \\
\hline & & Girls & & & & \\
\hline \multirow[t]{2}{*}{ CHILD component } & $1.410 * * *$ & 15.441 & 0.048 & $0.116^{* *}$ & 0.126 & 0.012 \\
\hline & $(0.511)$ & $(26.170)$ & $(0.063)$ & $(0.057)$ & $(0.084)$ & $(0.081)$ \\
\hline \multirow[t]{2}{*}{ Take-home rations } & -0.600 & $78.105^{* * *}$ & -0.053 & $0.219 * *$ & $0.475 * * *$ & -0.033 \\
\hline & $(0.968)$ & $(22.553)$ & $(0.134)$ & $(0.097)$ & $(0.176)$ & $(0.119)$ \\
\hline \multirow[t]{2}{*}{ Food management committee trained } & -0.211 & -1.751 & -0.061 & -0.065 & 0.026 & -0.074 \\
\hline & $(0.461)$ & $(17.023)$ & $(0.062)$ & $(0.054)$ & $(0.064)$ & $(0.062)$ \\
\hline \multirow[t]{2}{*}{ Cooks trained } & $1.026 * *$ & 23.146 & 0.074 & -0.034 & -0.017 & 0.086 \\
\hline & $(0.462)$ & $(13.961)$ & $(0.063)$ & $(0.054)$ & $(0.072)$ & $(0.060)$ \\
\hline \multirow[t]{2}{*}{ Disruption in food distribution } & $1.716^{* *}$ & - & -0.094 & -0.077 & -0.175 & -0.144 \\
\hline & $(0.720)$ & - & $(0.094)$ & $(0.088)$ & $(0.125)$ & $(0.095)$ \\
\hline \multirow[t]{2}{*}{ Meals served at half-way } & $-1.049 * *$ & 14.116 & -0.041 & -0.027 & -0.062 & -0.084 \\
\hline & $(0.508)$ & $(25.317)$ & $(0.059)$ & $(0.048)$ & $(0.065)$ & $(0.085)$ \\
\hline \multirow[t]{2}{*}{ Meals served at end of school day } & $-1.904 * *$ & -47.849 & $-0.211 * *$ & $-0.188 * * *$ & -0.086 & $-0.289 * *$ \\
\hline & $(0.902)$ & $(31.584)$ & $(0.082)$ & $(0.069)$ & $(0.184)$ & $(0.118)$ \\
\hline \multirow[t]{2}{*}{ School meals programme duration } & $0.118 *$ & 4.347 & -0.005 & 0.002 & -0.007 & 0.008 \\
\hline & $(0.063)$ & $(2.747)$ & $(0.008)$ & $(0.006)$ & $(0.009)$ & $(0.010)$ \\
\hline \multirow[t]{2}{*}{ Cash contribution } & -0.103 & 48.843 & $0.635^{*}$ & -0.031 & -0.393 & -0.148 \\
\hline & $(3.554)$ & $(63.155)$ & $(0.350)$ & $(0.193)$ & $(0.407)$ & $(0.275)$ \\
\hline \multirow[t]{2}{*}{ Material contribution } & -4.756 & 25.264 & 0.379 & -0.343 & -0.267 & -0.302 \\
\hline & $(3.610)$ & $(79.721)$ & $(0.381)$ & $(0.236)$ & $(0.414)$ & $(0.326)$ \\
\hline $\mathrm{N}$ & 252 & 112 & 277 & 277 & 277 & 277 \\
\hline
\end{tabular}


Table 8: School meals programme modalities and learning outcomes, by age (7-10 vs $11-13)$

\begin{tabular}{|c|c|c|c|c|c|c|}
\hline & $\begin{array}{c}(1) \\
\text { Raven's } \\
\text { test }\end{array}$ & $\begin{array}{c}\text { (2) } \\
\text { Concentration }\end{array}$ & $\begin{array}{c}(3) \\
\text { Reads } \\
\text { words }\end{array}$ & $\begin{array}{c}(4) \\
\text { Reads } \\
\text { sentences }\end{array}$ & $\begin{array}{c}(5) \\
\text { Writes }\end{array}$ & $\begin{array}{l}\text { (6) } \\
\text { Math }\end{array}$ \\
\hline \multicolumn{7}{|c|}{ Age 7 to 10 years old } \\
\hline \multirow[t]{2}{*}{ CHILD component } & 0.332 & -21.786 & -0.088 & -0.043 & -0.055 & -0.038 \\
\hline & $(0.482)$ & (21.774) & $(0.058)$ & $(0.048)$ & $(0.053)$ & $(0.077)$ \\
\hline \multirow[t]{2}{*}{ Take-home rations } & -1.500 & 38.1 & -0.107 & 0.143 & $0.409^{* * *}$ & 0.114 \\
\hline & $(0.972)$ & $(19.6$ & $(0.121)$ & $(0.109)$ & $(0.096)$ & $(0.135)$ \\
\hline \multirow[t]{2}{*}{ Food management committee trainec } & -0.139 & -12.056 & -0.072 & $-0.100 *$ & 0.003 & -0.076 \\
\hline & $(0.472)$ & $(10.8$ & $(0.051)$ & $(0.053)$ & $(0.049)$ & $(0.060)$ \\
\hline \multirow[t]{2}{*}{ Cooks trained } & $1.105^{* *}$ & $29.992 * * *$ & 0.019 & 0.005 & -0.049 & 0.068 \\
\hline & $(0.458)$ & $(10.443)$ & $(0.054)$ & $(0.057)$ & $(0.049)$ & $(0.055)$ \\
\hline \multirow[t]{2}{*}{ Disruption in food distribution } & 1.129 & - & 0.015 & 0.062 & $-0.143 * *$ & -0.099 \\
\hline & $(0.699)$ & 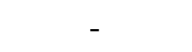 & $(0.063)$ & $(0.063)$ & $(0.067)$ & $(0.103)$ \\
\hline \multirow[t]{2}{*}{ Meals served at half-way } & $-0.907^{*}$ & -8.197 & -0.063 & -0.068 & -0.069 & -0.089 \\
\hline & $(0.460)$ & $(18$. & $(0.056)$ & $(0.045)$ & $(0.051)$ & $(0.071)$ \\
\hline \multirow[t]{2}{*}{ Meals served at end of school day } & -0.962 & -41.136 & -0.045 & -0.043 & -0.143 & $-0.287 *$ \\
\hline & $(0.760)$ & $(32$ & $(0.134)$ & $(0.122)$ & $(0.117)$ & $(0.161)$ \\
\hline \multirow[t]{2}{*}{ School meals programme duration } & 0.080 & $5.672^{* *}$ & 0.002 & 0.008 & -0.001 & 0.003 \\
\hline & $(0.063)$ & $(2$. & $(0.007)$ & $(0.006)$ & $(0.006)$ & $(0.008)$ \\
\hline \multirow[t]{2}{*}{ Cash contribution } & 3.615 & $129.451 *$ & 0.551 & -0.012 & $-1.015^{* * *}$ & * -0.625 \\
\hline & $(2.728)$ & $(65.6)(x)-x)$ & $(0.361)$ & $(0.362)$ & $(0.3$ & $(0.521)$ \\
\hline \multirow[t]{2}{*}{ Material contribution } & -1.539 & 87.279 & 0.297 & -0.354 & $-0.968^{* * *}$ & * $-0.877 *$ \\
\hline & $(2.811)$ & $(72.500)$ & $(0.391)$ & $(0.404)$ & $(0.345)$ & $(0.526)$ \\
\hline & 382 & 166 & 419 & 419 & 420 & 420 \\
\hline & Age 1 & 13 & & & & \\
\hline \multirow[t]{2}{*}{ CHILD component } & 0.827 & -30.038 & 0.104 & 0.111 & $0.172^{* *}$ & -0.043 \\
\hline & $(0.893)$ & $(18$ & $(0.098)$ & $(0.106)$ & $(0$. & $(0.070)$ \\
\hline \multirow[t]{2}{*}{ Take-home rations } & -1.001 & 57.426 & $0.387 * * *$ & $0.669^{* * * *}$ & $0.641 * * *$ & -0.087 \\
\hline & $(1.148)$ & $(42.981)$ & $(0.129)$ & $(0.124)$ & $(0.140)$ & $(0.098)$ \\
\hline \multirow[t]{2}{*}{ Food management committee trainec } & $1.120^{*}$ & 2.50 & 0.108 & 0.021 & 0.060 & $0.146^{* * *}$ \\
\hline & $(0.561)$ & $(19.3$ & $(0.073)$ & $(0.072)$ & $(0.069)$ & $(0.053)$ \\
\hline \multirow[t]{2}{*}{ Cooks trained } & 0.647 & 18.671 & 0.102 & 0.041 & $0.189^{* * *}$ & 0.074 \\
\hline & $(0.589)$ & $(25.084)$ & $(0.074)$ & $(0.069)$ & $(0.066)$ & $(0.054)$ \\
\hline \multirow[t]{2}{*}{ Disruption in food distribution } & 1.159 & - & -0.135 & -0.165 & -0.109 & -0.012 \\
\hline & $(0.893)$ & - & $(0.115)$ & $(0.117)$ & $(0.102)$ & $(0.107)$ \\
\hline \multirow[t]{2}{*}{ Meals served at half-way } & -0.379 & 30.229 & -0.004 & 0.042 & -0.037 & 0.026 \\
\hline & $(0.735)$ & $(23.543)$ & $(0.094)$ & $(0.094)$ & $(0.072)$ & $(0.074)$ \\
\hline \multirow[t]{2}{*}{ Meals served at end of school day } & -0.673 & 4.152 & -0.084 & -0.144 & -0.049 & 0.030 \\
\hline & $(1.086)$ & $(31.833)$ & $(0.148)$ & $(0.133)$ & $(0.119)$ & $(0.082)$ \\
\hline \multirow{2}{*}{ School meals programme duration } & 0.024 & 6.701 & -0.014 & -0.018 & -0.009 & -0.002 \\
\hline & $(0.111)$ & & $(0.011)$ & $(0.012)$ & $(0.010)$ & $(0.008)$ \\
\hline \multirow[t]{2}{*}{ Cash contribution } & 0.971 & 57.505 & $1.033^{*}$ & 0.157 & -0.262 & $0.929 * * *$ \\
\hline & $(4.787)$ & (72.934) & $(0.574)$ & $(0.413)$ & $(0.394)$ & $(0.236)$ \\
\hline \multirow[t]{2}{*}{ Material contribution } & -1.333 & 97.236 & 0.816 & 0.008 & 0.019 & $0.835^{* * *}$ \\
\hline & $(5.273)$ & $(83.181)$ & $(0.597)$ & $(0.477)$ & $(0.412)$ & $(0.260$ \\
\hline $\mathrm{N}$ & 183 & 93 & 188 & 188 & 190 & 189 \\
\hline
\end{tabular}

Note: $* \mathrm{p}<0.10, * * \mathrm{p}<0.05, * * * \mathrm{p}<0.01$. Standard errors in parentheses. In specification (2) the regressor Disruption in food distribution has been omitted because the concentration measure had been collected only for a subset of school catchment areas and it turned out that in this subset disruptions had occurred in all schools such that the regressor is without variation. 